Neurosurg Focus 24 (2):E18, 2008

\title{
Techniques in carotid artery surgery
}

\author{
Jonathan Andrew Curtis, F.R.A.C.S., And KaJ Johansen, F.R.A.C.S., Ph.D. \\ Swedish Neuroscience Institute and Swedish Medical Center, Cherry Hill Campus Seattle, Washington
}

\begin{abstract}
$\checkmark$ The major objective in carotid endarterectomy is to achieve safe and complete removal of intimal plaque and provide lasting, nonstenotic closure. Controversy exists as to which technical variation best achieves this. In this paper, the authors review the operative nuances and outcomes with conventional and eversion endarterectomy, with a focus on the latter. The views expressed reflect specific neurosurgical and vascular perspectives in the context of a multidisciplinary stroke unit, where carotid stenosis is managed with all available open and endovascular means. The neurosurgical approach was almost entirely conventional endarterectomy with primary repair, while the vascular surgeons used the eversion method with few exceptions. (DOI: 10.3171/FOC/2008/24/2/E18)
\end{abstract}

\author{
KEY WORDS • carotid artery • carotid endarterectomy • eversion endarterectomy • \\ history • stent • technique
}

\section{History of CE}

The establishment of extracranial CA surgery as an effective treatment option began with several operations and publications in the early 1950 s. Eastcott et al. ${ }^{31}$ published their account of carotid surgery for stroke prevention in London. These authors anastomosed the distal ICA to the proximal CCA with good results. At about this time, DeBakey independently performed his technique of carotid arteriotomy and repair. The success of this operation was documented many years later. ${ }^{28}$ Adding further validity to carotid surgery was a third publication by 3 neurosurgeons from Argentina who had similarly performed a direct endto-end anastomosis, but had joined the distal ICA to the proximal ECA. ${ }^{18}$ They had read Fisher's report concerning locally treatable carotid disease. ${ }^{39}$ Over the next few decades, there were many failures as the techniques were widely and loosely applied. ${ }^{32}$ Ultimately, due to persisting complications and deaths associated with the technique, the first randomized controlled trial to define the place that $\mathrm{CE}$ had in clinical practice was formulated.64 Following this, the role of conventional $\mathrm{CE}$ was established for symptomatic high-grade stenosis, and became widely accepted and practiced. ${ }^{27,43}$ Although highly effective, some limitations of the technique were noted. Recurrent stenosis was

Abbreviations used in this paper: $\mathrm{CA}=$ carotid artery; $\mathrm{CCA}=$ common $\mathrm{CA} ; \mathrm{CE}=$ carotid endarterectomy; $\mathrm{ECA}=$ external $\mathrm{CA}$; ICA = internal CA; IJV = internal jugular vein; MR = magnetic resonance; $\mathrm{SSEP}=$ somatosensory evoked potential; $\mathrm{TCD}=$ transcranial Doppler. seen, which at times required repeated treatment. Patching of the arteriotomy effectively solved this problem, but had its own unique set of drawbacks.

The concept of everting the diseased vessel rather than subjecting it to full longitudinal exposure was first conceived by DeBakey et al. in 1959. ${ }^{29}$ This technique involved everting the CCA from its proximal to its distal end. The procedure was technically difficult and ultimately abandoned. It was not until the late 1980s that Kazprzak and Raithel ${ }^{46}$ reexplored the eversion method, this time using the proximal ICA as the transection and eversion point. This procedure was technically much easier and was achieved with good results. The method was subsequently exported to Europe, and more recently returned to the US.

\section{Patient Selection}

In the major clinical trials in the 1990s in which CE was compared with best medical treatment, a number of clinical and radiological features were found to predict outcome reliably. The primary predictive factors were related to symptoms and degree of stenosis. ${ }^{36,64}$ Symptomatic disease with stenosis of $\geq 60-70 \%$ is a strong indication for surgery. Asymptomatic lesions with $>70 \%$ stenosis will also benefit from surgery in the longer term, provided the rate of perioperative complications is low. ${ }^{37}$ Occasionally, consideration for surgery will be given to an ulcerated lesion with a lesser degree of stenosis due to its prognostic significance, particularly if there are active emboli visible on TCD ultrasonography that have been refractory to medical 
treatment. ${ }^{30,62,74}$ Diagnostic workup from a neurosurgical standpoint includes multislice computed tomography angiography and TCD ultrasonography. If there is heavy calcification or the suggestion of near occlusion, cerebral angiography is performed to clarify carotid patency. In contrast, carotid duplex imaging is the diagnostic workhorse of our vascular surgeons, with computed tomography angiography or MR angiography as secondary tools. If there have been any recent neurological symptoms, an MR image is obtained to determine the presence and size of any ischemic lesions. This helps to determine the timing and appropriateness of surgery.

Patients are referred for nonsurgical treatment for many reasons. A completed ipsilateral disabling stroke is an obvious contraindication to surgery, but patients with acute neurological instability also fare poorly with acute surgery. ${ }^{80}$ Other relative contraindications include atypical anatomy such as a high bifurcation, hemodynamically relevant tandem lesions, radiation-induced stenosis, and recurrent disease. ${ }^{47,60,67}$ Poor renal, cardiac, and pulmonary function also strongly predispose patients to poor surgical outcomes. ${ }^{15,25,67}$ Most studies also show significantly worse outcomes in patients $>75$ years of age..$^{19,44}$ At times, a filling defect is noted on imaging representing luminal thrombus. This should not be treated surgically due to the high perioperative stroke risk. In the above situations, if revascularization is warranted, strong consideration should be given to endovascular therapy with CA stent placement. The SAPPHIRE trial ${ }^{84}$ is 1 of several trials that has been used to support the use of CA stent placement in this context. This study demonstrated that CA stent placement caused significantly fewer complications compared with surgery, and this technique is expected to be used more widely in the future. However, given the outcomes of recent large, multicenter European trials, caution should be used in advising that this be a standard treatment for non-high-risk individuals, particularly if their lesions are asymptomatic. ${ }^{14,54,58,77,82,87}$

\section{Technique for Conventional CE}

\section{Anesthesia Considerations}

Opinion on the choice of anesthetic agent for CE continues to be widely divergent among CA surgeons. Most vascular surgeons prefer to use regional or local anesthesia; ${ }^{16,20}$ this is the case at our institute. The benefits to this approach are that it permits neurological monitoring and possibly greater hemodynamic stability. Regional blocks can be directed to the superficial cervical plexus or to the deep cervical plexus. The latter technique may occasionally result in major vascular or nerve injury, and is not mandatory. ${ }^{79} \mathrm{~A}$ combination of lidocaine and bupivicaine is used. The majority of neurosurgeons continue to prefer general anesthesia. This preference may be related to the frequent use of intraoperative physiological monitoring, or concern over the rare but possible situation in which there is rapid neurological and/or respiratory compromise requiring intubation. ${ }^{26}$ In both approaches, thorough preparation and continuous monitoring are required throughout surgery. This mandates a well-functioning arterial line, adequate venous access, and readily accessible inotropic support as needed for cross-clamping.

\section{Intraoperative Monitoring}

Surgeons who prefer local anesthesia rely heavily on intermittent neurological checks to assess perfusion. Continuous, motor, speech, and cognitive assessments are ideal but impractical. Most such surgeons rely on contralateral motor response testing. Language barriers, aphasia, and confusion related to recent or past strokes can limit the efficacy of intraoperative assessments, and in these cases general anesthesia is considered. Stump pressures and qualitative backflow measurements also provide crude intraoperative feedback concerning the adequacy of the collateral vessel. Electroencephalography, SSEPs, and TCD ultrasonography are the modalities used most often. Intraoperative electroencephalography has the longest track record for use during $\mathrm{CE}$, having now been utilized for $>50$ years. This modality is highly sensitive to blood flow changes, and like SSEPs, it detects reduced regional blood flow to levels around $16-18 \mathrm{ml} / 100 \mathrm{~g} / \mathrm{min}^{40,51,85}$ The interpretation of changes requires a solid working knowledge of the expected changes with varying depths of anesthesia. ${ }^{21,57,71}$ If a unilateral change is seen with cross-clamping, the appropriate measure is to induce hypertension and administer cerebral protection. Somatosensory evoked potentials are used to measure cortical electrical activity in response to peripheral stimuli. Serially recorded responses are compared with normative laboratory values. The processing times and number of sweeps required for averaging the values mean that clinically relevant findings may be slightly delayed. The specific pattern of change seen will depend on the individual collateral vessels. Asymmetry in amplitude, shape, and secondarily an increase in the latency period is a common marker of ischemia. Somatosensory evoked potentials are more sensitive to subcortical ischemia, and have a high positive predictive value. When TCD is used, the frame is placed prior to surgical positioning, and the signals are checked. The TCD team monitors middle cerebral artery velocity and pulsatility throughout the procedure, and also monitors microembolic signals indicating an active embolism. ${ }^{83}$ These are reliably diagnosed with strict audio and visual criteria. In continuously monitored patients undergoing $\mathrm{CE}$, microembolic signals have been reported in up to $90 \%$ of cases. ${ }^{2,42,78}$ This also helps to determine whether a shunt is needed. When general anesthesia is used, we recommend using all 3 of the above modalities.

\section{Patient Positioning and Preparation}

The patient is typically placed supine, with some form of central shoulder elevation to minimize the natural concavity of the anterior neck and shoulder region. The head is rotated $10-15^{\circ}$ to the contralateral side, and gently extended at the craniocervical joint to move the mandible superiorly and further open up the anterior neck triangles. However, too much rotation should be avoided so that the IJV will remain lateral rather than anterior to the CA. Some degree of the reverse Trendelenburg position is useful for surgeon comfort and optimizing venous return. An Lshaped support or Layla bar is fixed to the operating table to provide the necessary access for airway observation and access. The surgical area is usually cordoned off with plastic drapes and it is essential to include as wide an area as 


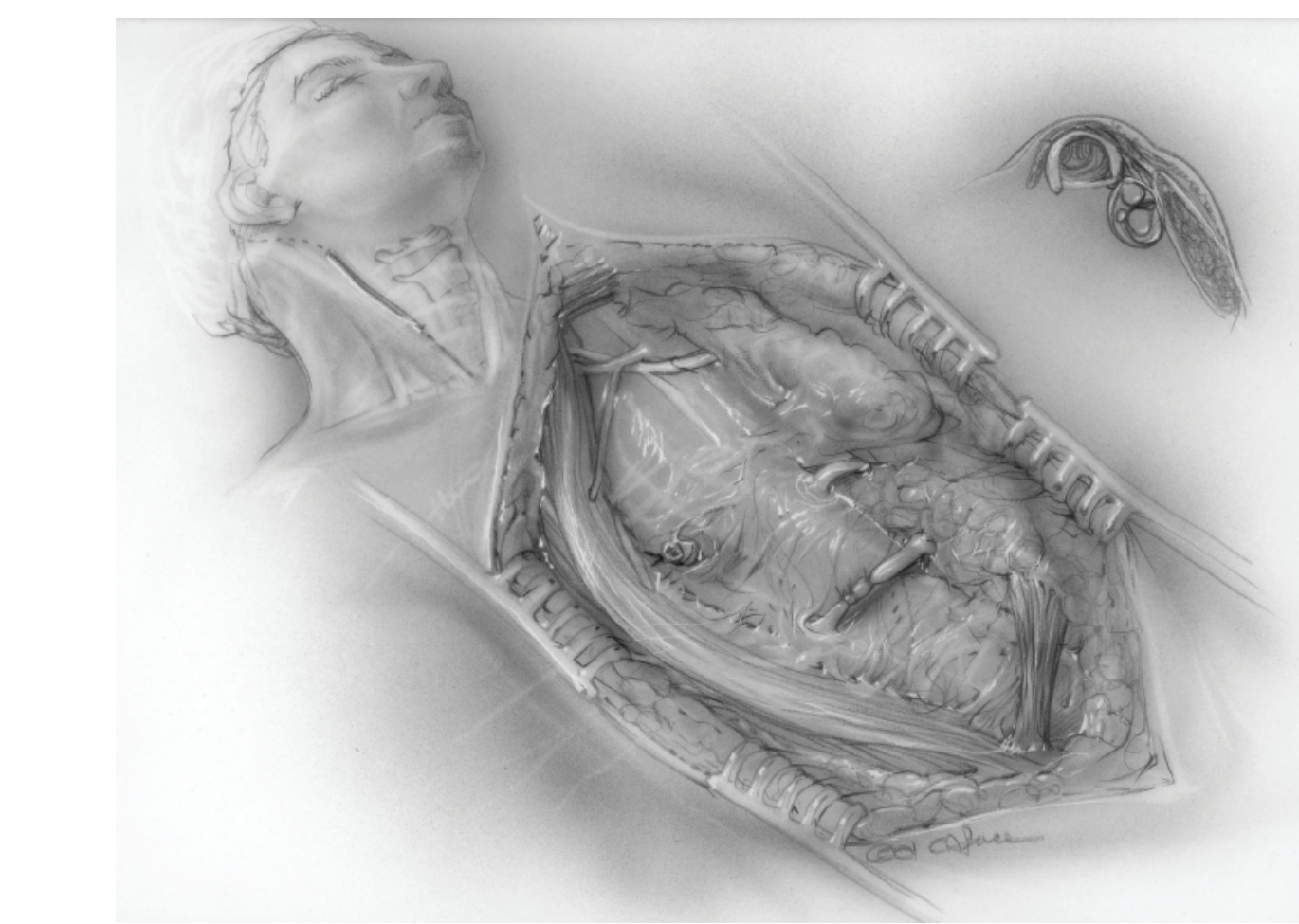

FIG. 1. Artist's illustration of the early phase of dissection. The sternocleidomastoid is retracted, revealing the carotid sheath. Vascular relationships of the hypoglossal nerve and ansa cervicalis are seen superiorly. Velez DA, Newell DW: Ischemic stroke and carotid endarterectomy, in Moore AJ, Newell DW (eds): Neurosurgery: Principles and Practice. New York: Springer-Verlag, 2004, pp 651-670. Fig. 38.2. With kind permission from Springer Science and Business Media.

possible, incorporating the mastoid and ear lobe superiorly, the midline medially, and the sternoclavicular joint inferiorly. A topical antiseptic agent is then applied carefully to avoid the possibility of manually provoked emboli. A single dose of an intravenous antibiotic agent is given when anesthesia is induced. The incision is marked at the anterior border of the sternocleidomastoid muscle and curved posteriorly toward the mastoid process to avoid the marginal mandibular branch of the facial nerve (Fig. 1). It is possible to use a transverse skin crease incision, but the exposure is more likely to be compromised. Loupe magnification is helpful for the arteriotomy and for high exposures.

\section{Conventional Technique Without Patching}

After dividing the superficial fat and usually some of the transverse cervical nerves, the platysma muscle is identified and divided longitudinally. Constant attention to hemostasis is critical from the outset. Deep to the platysma lies a fat layer containing tributaries of the IJV and glandular tissue superiorly, which overlies the sternocleidomastoid muscle. The anterior border of this layer is the key landmark for early dissection. Care should be taken to stay below the submandibular gland and adjacent lymph nodes. The largest venous tributary here is usually the facial vein, which is isolated, divided, and then placed under tension to move the IJV laterally. The proximal end of this tributary drains to the IJV, which lies lateral and superficial to the CCA. The site of this division also corresponds to the level of the carotid bifurcation and acts as a useful landmark. The carotid pulse is lightly palpated to direct further sharp dissection, beginning inferiorly. Once the CCA is identified, the bifurcation is located superiorly (Fig. 1). A single, weight-based bolus of heparin is administered when the CA is exposed. It is imperative to develop and maintain the plain immediately external to the adventitia to avoid excessive and unnecessary dissection. Circumferential exposure is needed only for the segment where vessel loops are to be applied, but great care must be taken posteriorly where the vagus nerve is most likely to be encountered, and at the bifurcation where the plaque is most vulnerable with the ICA as yet unclamped.

The ECA is easily identified by its branches and lies superficial to the ICA. Once identified, the ECA is dissected out and labeled with a colored Vessiloop (Getz Bros) and mild traction directed inferomedially is applied to assist with upper ICA exposure. A light hemoclip is applied to the superior thyroid artery. The medially directed superior thyroid artery origin must also be exposed. The ICA is usually found posterolaterally, and is progressively exposed above the bifurcation. The hypoglossal nerve is another important landmark, and runs superficial to both the ICA and ECA main trunks, and is tucked under the posterior belly of the digastric muscle. The nerve is slung by a sternocleidomastoid arterial branch of the occipital artery; dividing this allows mobilization of the nerve superomedially and improved distal exposure (Fig. 2). A guide to it is the descendens hypoglossi, which can be followed superiorly. 


\section{J. A. Curtis and K. Johansen}
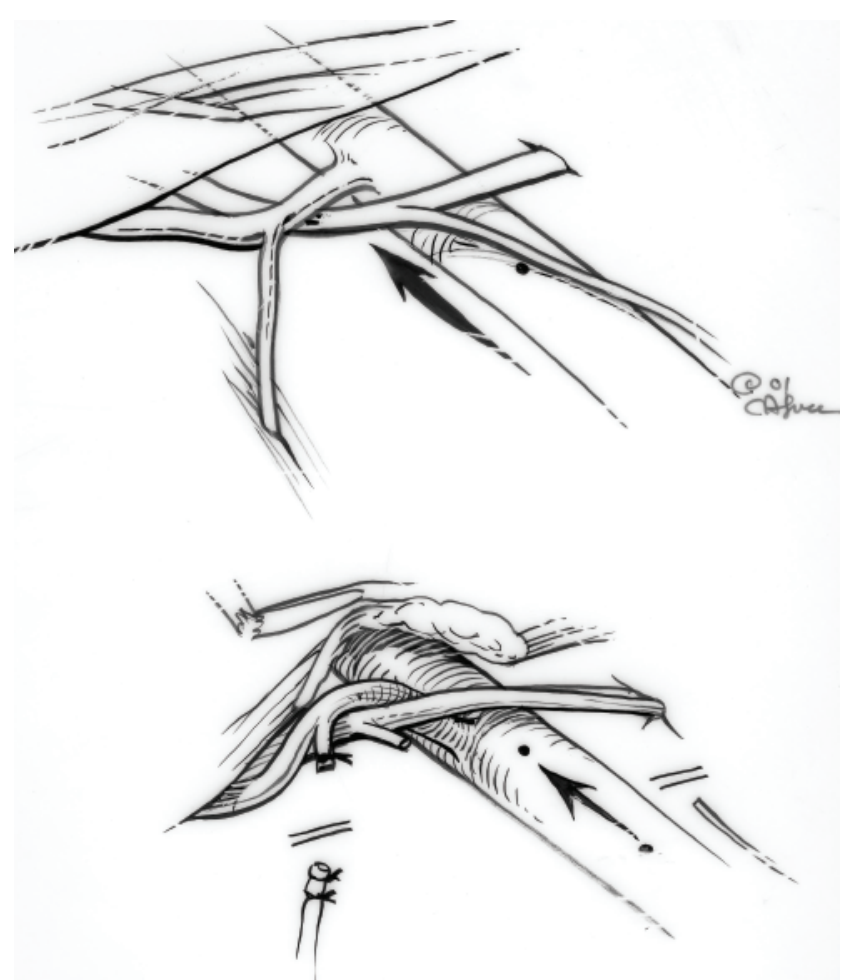

FIG. 2. Artist's illustration of hypoglossal mobilization. With the descendens hypoglossi and the sternocleidomastoid branch of the occipital artery divided or mobilized, the hypoglossal nerve (upper arrow) is released and easily displaced superomedially for better rostral exposure (lower arrow). Velez DA, Newell DW: Ischemic stroke and carotid endarterectomy, in Moore AJ, Newell DW (eds): Neurosurgery: Principles and Practice. New York: Springer-Verlag, 2004, pp 651-670. Fig. 38.3. With kind permission from Springer Science and Business Media.

The critical determinants of the required superior exposure is extent of the plaque and of course the bifurcation level. Atheroma is visible as a whitish-yellow discoloration of the artery and is firm and noncompressible relative to a healthy artery. A reasonable segment of non-diseased artery should be accessible above the upper limit of the plaque to allow sufficient workspace for accessing the distal end point. Distal control of the ICA is then achieved.

Once sufficient proximal and distal exposure is achieved and all 4 vessels are secured, cross-clamping can begin. The surgeon should pause at this point to ensure that the necessary equipment and assistance is immediately available, and that the anesthesiologist can maintain or increase the patient's blood pressure if needed. The arteriotomy line is marked out. When TCD is being used, trial cross-clamping of the distal ICA above the plaque is performed. Middle cerebral artery velocities are observed, and shunt placement is considered if velocities $<50 \%$ of baseline are sustained and do not respond to hypertensive measures. ${ }^{78}$ The diseased portion of the ICA and distal CCA are then trapped. A temporary aneurysm clip is a good choice for the ICA, and an angled soft clamp for the CCA. A soft portion of the CCA is sought for clamp placement to allow lumen occlusion without plaque fracture. A separate clamp or another aneurysm clip can be used for the ECA. The

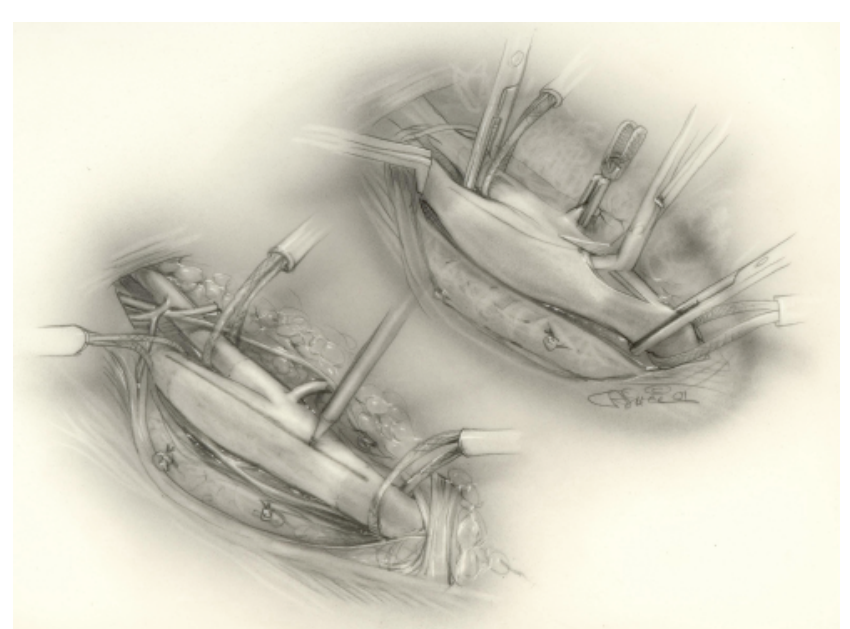

FIG. 3. Artist's illustration of the arteriotomy. With all vessels isolated and clamped, the arteriotomy is marked out and carefully performed, beginning at the CCA. Velez DA, Newell DW: Ischemic stroke and carotid endarterectomy, in Moore AJ, Newell DW (eds): Neurosurgery: Principles and Practice. New York: Springer-Verlag, 2004, pp 651-670. Fig. 38.4. With kind permission from Springer Science and Business Media.

final clamp positions should be easily accessible but not cluttering the operative field.

\section{Arteriotomy Procedure}

In a standard CE, the arterial incision commences at the CCA and is extended distally. We use a No. 11 blade for entering the lumen. Potts scissors can then be used to extend the opening distally (Fig. 3). The opening should be smooth and single-walled. Heavily calcified plaque is often encountered, necessitating the use of sharp, medium-sized instruments. The incision is extended above the distal end point into the normal artery. At this point some surgeons check ICA back bleeding as a crude measure of stump pressure and collateral artery support. The correct endarterectomy plain must then be established and developed. This is best commenced over the thickest part of the plaque with a broad-tipped, straight or mild-angle dissector, such as the Frier. After the correct plain is established, the outer border of the plaque easily separates from the residual arterial wall. This plain is then progressively developed both proximally and distally, and around the circumference of the artery, with care taken to avoid perforation of the remaining incomplete arterial back wall. The objective is to leave as much arterial wall in place as possible while removing all of the plaque (Fig. 4). A medium-sized rightangle retractor can assist with the posterior plaque elevation. A stump is left at the ECA orifice for later removal. At the distal end point the plaque will feather out as it blends with a thickened intima. Occasionally the distal ICA will not be totally free from intimal disease. In this case it is difficult to entirely eliminate a plain of dissection that could lead to a distal flap, and the use of 1 or more tacking sutures, because security against a distal dissection should be considered. Trimming back with microscissors or a small Potts scissors can also be effective. The surgeon's proximal end point on the CCA is more subjective, as the plaque 


\section{Techniques in carotid artery surgery}

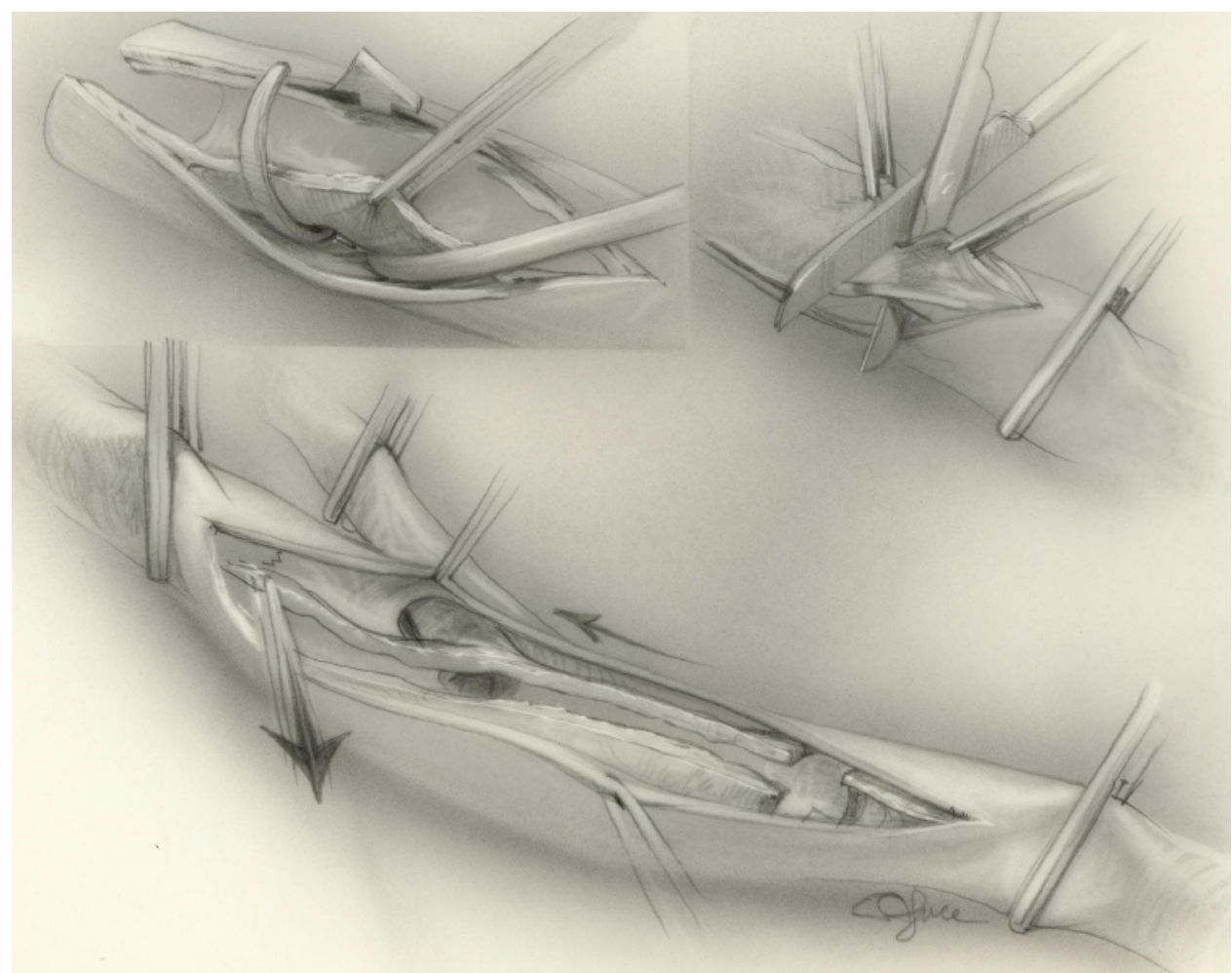

FIG. 4. Artist's illustration of the endarterectomy. Establishing and maintaining the plain of plaque elevation is paramount. Dividing the plaque as illustrated will assist in its removal. Arrows indicate the direction of plaque dissection. Velez DA, Newell DW: Ischemic stroke and carotid endarterectomy, in Moore AJ, Newell DW (eds): Neurosurgery: Principles and Practice. New York: Springer-Verlag, 2004, pp 651-670. Fig. 38.5. With kind permission from Springer Science and Business Media.

commonly extends to the aortic arch. The best approach is to establish a sharp, smooth cut-off with Potts scissors immediately distal to the proximal arteriotomy point. This allows good visibility and the safe removal of all potentially embolizable fragments.

The stump in the ECA is then similarly removed (Fig. 5). Temporary clamps here are sometimes removed to assist with a more complete evacuation from the ECA. Copious amounts of heparinized saline solution should be used at this point to remove small debris and assist in defining any areas of incomplete plaque removal. Circumferential medial fibers are typically seen, and in general should be left unless mobile. The stage is now set for primary closure.

The most crucial aspect of closure is the distal ICA, where vessel caliber is smallest. To prevent iatrogenic stenosis, one has to take the minimum full-thickness suture depth required for competent closure. A double-armed 6.0 Prolene suture is commonly used, with each arm making a bite close to the apex of the arteriotomy and tied externally. The knot is laid down on the vessel with the first few stitches, and then followed. The stitches should be regularly spaced and of full thickness. The compromise is between a tight, nonleaky closure, and minimizing the fibrotic reaction known to correlate with foreign body load. The forceps and needle-holding technique should be well practiced, the needle passing without causing injury and at $90^{\circ}$ to the vessel wall. Ringed forceps act as effective pick-ups. The proximal suturing is either continued from above, or a second 5.0 or 6.0 suture can be started at the lower apex and ultimately tied at the midportion (Fig. 5).

Prior to the final tying, the patency of the repair should be assessed. Back bleeding from the ICA is helpful as this gives further information concerning stump pressure and confirms distal patency. The CCA or ECA may also be used to assess patency. It is of utmost importance to ensure that the intraluminal fluid compartment is full prior to complete restoration of flow, ${ }^{1}$ and that there is no foreign material in the lumen. Once the suturing is complete, the clamps are sequentially removed. The ECA is released first, followed by the CCA. This technique permits any residual debris to be flushed into the relatively noncritical extracranial circulation. Finally the ICA is released, restoring full intracranial flow. Careful inspection of the arteriotomy line is required and any pulsatile leakage repaired with additional sutures. Nonpulsatile leakage is gently packed with Gelfoam (Pfizer) or another hemostatic agent until it is controlled. It is our practice not to reverse heparin therapy. Meticulous attention must be paid to wound hemostasis, and a layered wound closure performed over the drain. A functioning drain should be established before dressings are applied.

\section{Use of a Patch}

For many surgeons, patching represents the standard practice to ensure against restenosis. It is particularly useful in patients with congenitally small CAs. The 2 common techniques are to use autologous vein graft material, usual- 


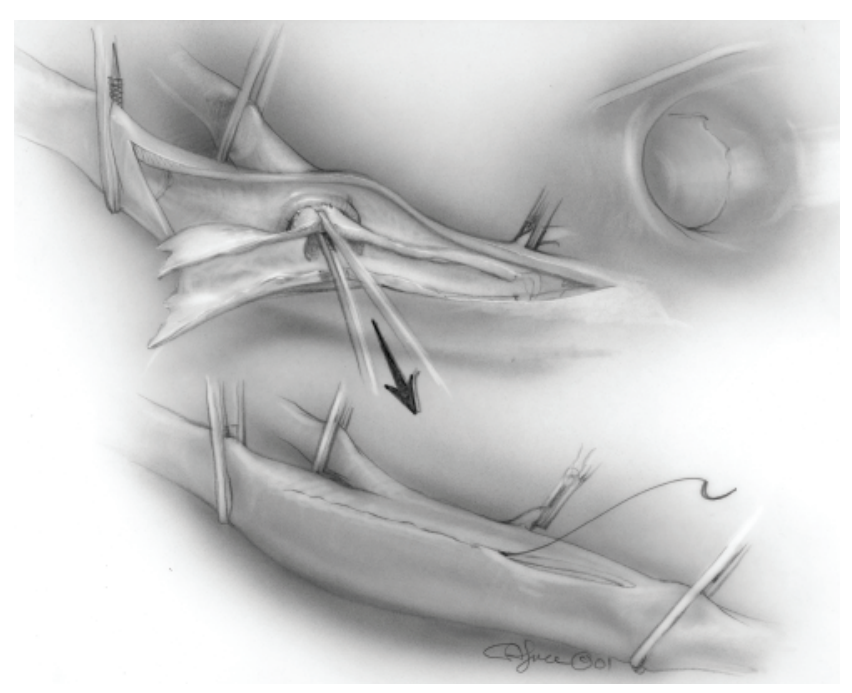

FIG. 5. Artist's illustration of the ECA. Prior to closure the ECA stump is dissected out and back bleeding is assessed. Arrow indicates direction of plaque removal. Velez DA, Newell DW: Ischemic stroke and carotid endarterectomy, in Moore AJ, Newell DW (eds): Neurosurgery: Principles and Practice. New York: Springer-Verlag, 2004, pp 651-670. Fig. 38.6. With kind permission from Springer Science and Business Media.

ly from the saphenous vein, or a synthetic suturable material. A double-armed 24-inch 5-0 Prolene suture is used, commencing distally. The suture is passed from the apex of the graft to the ICA and tied. Small, close stitches are performed here. Each suture is then run sequentially and the graft trimmed to create the desired lumen size. For a more detailed overview on patching and shunt placement techniques the reader is referred to other sources..$^{38,60}$

\section{Eversion CE}

Our method is based on the work of Kazprzak and Raithel, ${ }^{46}$ and in terms of positioning, setup, and exposure, there is little to separate the approaches. Both require thorough exposure of the carotid vascular tree from the CCA to the nondiseased portion of the distal ICA and proximal ECA, with careful identification and preservation of nerves in and adjacent to the carotid sheath and the hypoglossal nerve. Because complete mobility of the ICA is eventually required, thorough dissection away from the surrounding soft tissue is critical prior to endarterectomy. This includes the posterior wall of the ICA, which theoretically places the vagus nerve and its branches at greater risk, and requires some additional manipulation of the bifurcation region..$^{53}$ To counter the embolism risk associated with this increased dissection, we apply a curved soft clamp to the distal ICA as early as practicable.

Once the exposure is adequate and intravenous heparin has circulated, the arterial work can begin. Provided that there is no significant redundancy in the proximal ICA, the site of the arteriotomy is at its origin. A pair of curved Mayo scissors are effective for the initial transection. The scissors are placed with the crook of the instrument at the rostral bifurcation and the blades encircling the ICA, directed inferolaterally. A sharp, oblique, and complete cut is desired. With the ICA now mobile, the proximal part of the arteriotomy is "fish-mouthed" to create the distal heel. This shortens the segment to be everted and also helps to address any redundancy. The endarterectomy plain is then established circumferentially to the ICA. With gentle and con-

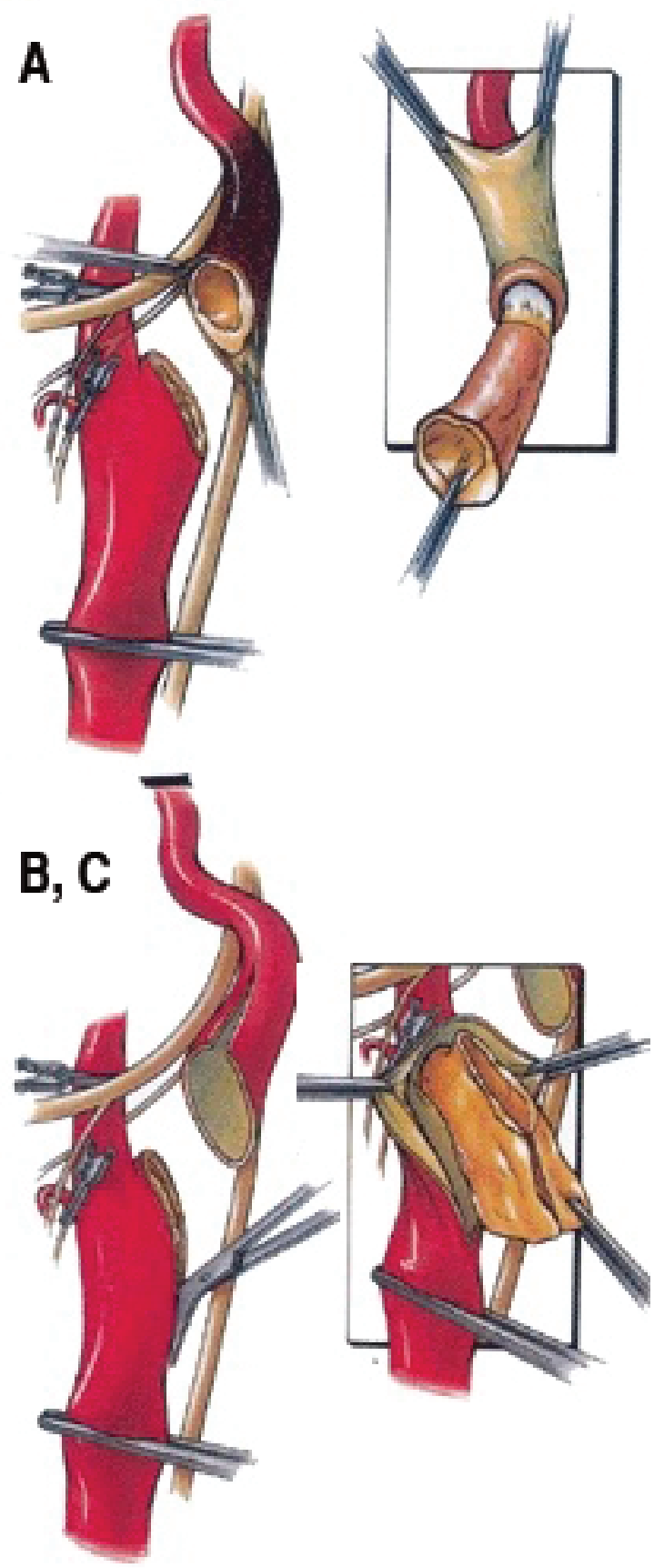

FIG. 6. Artist's illustration of the eversion endarterectomy. In the popular Kazprzak technique, the transection and anastomotic work is done at the ICA origin (A). Small arteriotomies on the CCA and the ICA assist with the endarterectomy and in creating a wide orifice for closure (B and C). Berger R, Kieffer E: Repair of the internal and external carotid arteries, in Surgery of the Arteries to the Hands. New York: Springer-Verlag, 1992, pp 108-133, Fig. 8.12. With kind permission from Springer Science and Business Media. 
stant downward traction applied to the plaque by an assistant, the normal outer arterial layer is peeled back rostrally or "everted" to deliver the plaque (Fig. 6). The everted position of the residual outer arterial wall should be maintained until the end point is adequately and thoroughly visualized. Using this technique, the plaque appears tapered or bullet-shaped, and is seen to feather out at its upper margin. The everted edges are inspected for residual plaque and irrigated with heparinized saline, as is the lumen. Assessment of ICA back bleeding is again useful for establishing distal patency.

Attention is then directed to the CCA and ECA complex. The arterial opening is extended obliquely onto the CCA to later accommodate the toe (distal part) of the transected ICA. This also assists with pseudoeversion of the CCA and proximal plaque extraction. Early in the plaque elevation, a right angle is used to complete the circumferential separation, and the plaque is then divided sharply below the ECA orifice into 2 portions. The technique for endarterectomy is then repeated with 1 surgeon applying traction to the plaque while countertraction and eversion of the parent artery is performed by the other surgeon. The lower end of the plaque is arbitrarily truncated with scissors according to the standard technique. The maneuver is then repeated to remove plaque from the ECA. The lumen of the entire complex is again thoroughly inspected and irrigated for residual disease, and the edges aligned for fit. The lateral edges of the fish-mouthed area of the ICA may need to be trimmed slightly for a better fit.

The closure is then an end-to-side fish-mouthed anastomosis. We begin with the stitch at the proximal end of the artery (the "heel") using a double-armed 6.0 Prolene suture, $1 \mathrm{arm}$ through the transected ICA and the other through the nonmobile proximal bifurcation. This is then anchor tied. Due to the end-to-side configuration, it is very difficult to narrow the artery at the suture line, which is a key advantage of the eversion method. A continuous back-wall suture is then run, ending in the toe region of the ICA, but exiting at the adjacent CCA. The front wall is completed in a like manner from the distal to the proximal end, meeting the other suture at the toe. Prior to the final tying, the same method of temporary back bleeding, tying, and then sequential clamp release is used. The anatomical new bifurcation and proximal ICA is immediately evident. Careful inspection of the front and back wall is performed to ensure that no additional sutures are needed, then a similar layered closure over a functioning drain is made without reversal of anticoagulation therapy. We commence a slow dextran infusion once the anastomosis is completed and continue this for 12 hours.

\section{Approach to Atypical Lesions}

Given the enormous progress made with endovascular carotid revascularization, the role for more extensive skull base exposures is becoming very small. Traditionally, high bifurcations were an indication for using this technique. By using a nasal intubation, and extending the incision rostrally, the upper extracranial ICA can be accessed. Great care must be taken, and visualization optimized due to the convergence of numerous lower cranial nerves here. The parotid capsule is defined, the seventh cranial nerve identified, and then the posterior belly of the digastric and stylohyoid muscle, and the stylomandibular ligaments can be successively divided. To assist further with this superior access, mandibular dislocation can also be used. Some authors have advocated the use of an operating microscope to improve the safety of the dissection..$^{38,60}$

\section{Postoperative Care}

Postoperative problems are common after CE and can range from relatively mild blood pressure changes to rapidly progressive airway compromise. Because of this, it is critically important that the patient receives adequate monitoring and vigilance. ${ }^{55}$ The ability and means to intervene should be readily available should a problem arise. The neurosurgical team at our institution closely monitors patients in the intensive care unit, with clinical and TCD surveillance. We also set strict individual blood pressure targets to avoid extremes. Heparinization is commenced if there are persisting, significant emboli. Aspirin therapy is begun the day after surgery. Our vascular team prefers to use an extended stay in the recovery ward for wound and airway observation. Once patients are stable, they are transferred to a dedicated surgical floor for overnight assessment. A dextran drip was used routinely in the eversion group and antiplatelet agents continued perioperatively.

\section{Postoperative Complications}

There are many physiological factors that combine to predispose patients to complications after CE. ${ }^{61}$ These include the use of anticoagulation medications, higher bulk flows, and a history of chronic ischemia and hypertension. It is not surprising then that even under the best conditions at institutions with highly experienced surgeons and nursing staff there is a reported 3-6\% major complication rate. ${ }^{70}$ Dissection-related complications such as nerve injury, wound infection, and parotid fistulas are relatively uncommon. The hypoglossal, vagus, superior laryngeal, marginal mandibular, and even the sympathetic plexus can be injured, causing significant cosmetic or, more commonly, swallowing and masticatory difficulties. The injuries can be devastating if partial contralateral injuries were unrecognized preoperatively. A wound hematoma is likely to occur in $\sim 5-8 \%$ of cases. It is critical to differentiate between an arteriotomy-related collection and a soft-tissue ooze. The former arises early with progressive wound swelling and may lead to airway compromise. Postoperative hypertension is a risk factor. ${ }^{63}$ This must be recognized immediately, and usually requires surgical exploration of the wound and the placement of additional sutures in the arteriotomy. Nonprogressive small hematomas can be managed with observation, but should be observed in an intensive care unit. The bleeding source here may be from the soft tissues secondary to inadequate hemostasis.

Ischemic complications may be either hypoperfusion-related or thromboembolic. The latter is probably a far more common cause of CE. ${ }^{4,11,52,86}$ Even with meticulous technique, the entire endarterectomized and anastomotic surface has been made highly thrombogenic with exposed collagens. Of course technical errors resulting in significant angulation, irregular suture lines, or a distal flap may also lead to thrombosis and vascular occlusion. Transcranial Doppler ultrasonography may help reduce the burden of perioperative cerebral ischemia. With serial emboli moni- 
TABLE 1

Summary of the major studies comparing conventional and eversion CE techniques*

\begin{tabular}{|c|c|c|c|c|c|c|c|c|}
\hline \multirow[b]{2}{*}{ Authors \& Year } & \multirow{2}{*}{$\begin{array}{l}\text { Type of } \\
\text { Study }\end{array}$} & \multirow{2}{*}{$\begin{array}{l}\text { No. of } \\
\text { eCEs }\end{array}$} & \multirow{2}{*}{$\begin{array}{l}\text { No. of } \\
\text { cCEs }\end{array}$} & \multirow{2}{*}{$\begin{array}{c}\text { No. } \\
\text { Patched }\end{array}$} & \multirow{2}{*}{$\begin{array}{l}\text { Length of } \\
\text { FU (mos) }\end{array}$} & \multirow[b]{2}{*}{ Findings } & \multicolumn{2}{|c|}{ Restenosis Rate (\%) } \\
\hline & & & & & & & eCE & $\mathrm{cCE}$ \\
\hline Vanmaele et al., 1994 & RCT & 102 & 98 & all & 11 & no significant lasting differences & 1 & 2.2 \\
\hline Cao P et al., 1998 & RCT & 678 & 675 & 256 & 33 & less need for shunt w/ eCE; same outcomes & 2.4 & 4.1 \\
\hline Balzer, 1998 & RCT & 286 & 278 & all & 24 & fewer periop neurological complications w/ eCE & 3.8 & 3.6 \\
\hline Ballotta et al., 1999 & RCT & 158 & 152 & all & 34 & less shunting needed in eCE \& fewer periop neurological events & 0 & 4.9 \\
\hline Ballotta et al., 2000 & RCT & 68 & 68 & all & 40 & fewer occlusive events $\mathrm{w} / \mathrm{eCE}$ & 0 & 4.7 \\
\hline Shah et al., 1998 & $\begin{array}{l}\text { retro- } \\
\text { spective }\end{array}$ & 1855 & 410 & NA & 18 & fewer periop \& long-term neurological complications w/ eCE & 0.3 & 1.1 \\
\hline
\end{tabular}

$* \mathrm{cCE}=$ conventional $\mathrm{CE} ; \mathrm{eCE}=$ eversion $\mathrm{CE} ; \mathrm{FU}=$ follow-up; $\mathrm{NA}=$ not available; periop = perioperative; $\mathrm{RCT}=$ randomized controlled trial

toring for periods of as little as $20-30$ minutes, an accurate measure of the presence, rate, and trend of emboli can be obtained, which correlate with stroke risk. ${ }^{2,52,78}$ The hyperperfusion syndrome is a relatively uncommon complication, and may present with diverse manifestations including focal neurological deficits, seizures, or generalized hemispheric dysfunction. ${ }^{23,76,86}$ There is also great variability in terms of the timing of symptom onset. ${ }^{10}$ Poor collateral circulation and postoperative hypertension are risk factors. On MR imaging studies, areas of restricted diffusion are not typically seen, but perfusion studies may show asymmetry. Frank intracerebral hemorrhage may also result. ${ }^{13}$ The management imperative is strict blood pressure titration.

\section{Discussion}

Effective plaque removal from a diseased CA can be achieved with both operative techniques. Conventional CE with or without the use of a patch has a long and proven track record in the management of carotid stenosis, and remains the gold standard technique ${ }^{36,64}$ Despite this, the eversion method is becoming more popular. Its key advantage is ease of arteriotomy and repair, and the widemouthed anastomosis produced without the need for a patch. The strength of this technique lies in the area of weakness of the other: lumen compromise on primary closure, and the vulnerabilities related to patching. There are also theoretical secondary advantages with the technique.

\section{Hemodynamic Consequences and Restenosis}

The nondiseased carotid bifurcation has a distinctive design and hemodynamic signature, characterized by a variable proximal diameter of the bulb region, and predictable streams of separated flow into the ICA.${ }^{66}$ Carotid revascularization should therefore be used in an attempt to restore anatomical conditions and flow patterns similar to the native normal vessel, which is the drive behind the widespread use of the patch technique in conventional CE. This has also been shown to reduce restenosis rates compared with primary closure. ${ }^{3,8,12}$ There is some evidence to suggest that eversion CE may produce even better hemodynamic changes than can be produced with patch angioplasty. With ultrasonography it has been shown that ICA dimensions, dynamic wall strain, and elastic modulus or the "stiffness" of the wall in patients who have undergone eversion CE closely mimics that seen in normal controls. ${ }^{8}$ In comparison, patches typically produce excessive lumens and decreased strain relative to the normal vessel ${ }^{84}$ Regardless of the type of patch used, they produce a composite reconstruction with discordant elastic and other material properties compared to the rest of the wall. This situation is less likely to be advantageous from a hemodynamic standpoint. Venous patches also suffer some additional problems, including delayed rupture, and may need to be routinely reinforced. ${ }^{60,65,73}$

Recurrent stenosis usually consists of neointimal hyperplasia and typically appears at the 10-12-month period postoperatively. It remains poorly understood and may be partly inflammatory and partly hemodynamic. The significance of restenosis lies in the fact that retreatment carries with it a greater complication rate. Primary closure is by far the most prone to this complication, occurring in 5-15\%, depending on the specific definition used, the technique employed, and the length of follow-up. . $33,34,48-50,72^{-1}$

Although vessels with patching are less prone to stenosis than primary closure, eversion may be even more effective (Table 1). In the series reported by Shah et al..${ }^{75}$ the rates of restenosis were close to 4 times less frequent $(0.3 \%$ in the eversion $\mathrm{CE}$ group, and $1.1 \%$ in the conventional $\mathrm{CE}$ group). In a randomized trial, Ballotta et al. ${ }^{6}$ showed no late restenosis in a group of patients who had undergone eversion, compared with $4.7 \%$ in their patched group. The pooled results from randomized trials comparing eversion with conventional treatments showed a statistically significant reduction in the incidence of delayed restenosis with eversion CE. ${ }^{17}$ In the largest series, Darling et al. ${ }^{24}$ reported a restenosis rate of $1.5 \%$. The authors of other studies have reported similar reductions in the need for revision surgeries secondary to restenosis. ${ }^{48-50,81}$

\section{Clamp Times and Cerebral Ischemia}

Probably the most significant advantage afforded by the eversion method is the shorter anastomosis times required. Radak and associates ${ }^{69}$ reported clamp times averaging 12.4 minutes in the latter part of their series of more than 5000 patients, and 14.5 minutes in the first group. The same authors reported significantly shorter clamp times with eversion than with conventional CE (13.5 and 19.9 minutes, respectively) in their earlier prospective study. ${ }^{68}$ Many other authors report the same findings, and the testimonies 

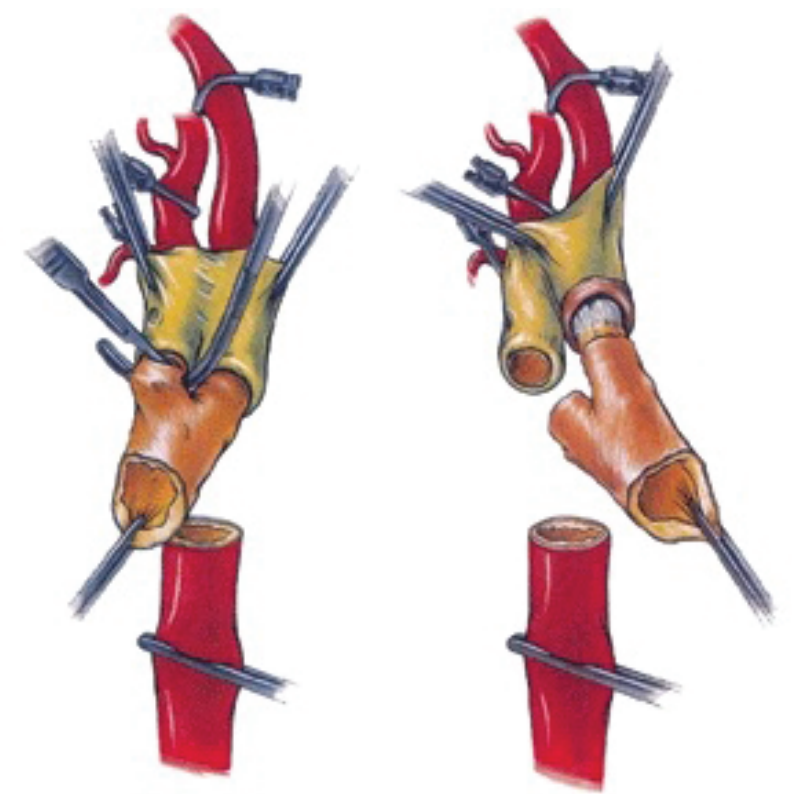

FIG. 7. Artist's illustration of the Etheredge technique. The point of transection is on the distal CCA. Velez DA, Newell DW: Ischemic stroke and carotid endarterectomy, Berger R, Kieffer E: Repair of the internal and external carotid arteries, in Surgery of the Arteries to the Hands. New York: Springer-Verlag, 1992, pp 108-133, Fig. 8.12. With kind permission from Springer Science and Business Media.

are reasonably consistent in stating that the commonly observed shorter ischemic times with eversion $\mathrm{CE}$ are due to the technically easier and structurally shorter anastomosis. ${ }^{9,41,45,56,75,81}$ The major reason for this is that the arteriotomy and repair are centered such that the operative field is less crowded, and concern about iatrogenic stenosis is essentially eliminated. This makes the suturing easier and more comfortable for the surgeon. With the confidence of a shorter clamp time, the need for a shunt may be dramatically reduced, as evidenced by the extremely low usage reported by Radak et al. ${ }^{69}$ and Darling and colleagues. ${ }^{24}$ Many surgeons have reported clamp times close to $10 \mathrm{~min}$ utes. ${ }^{50,69}$ This may be especially advantageous given the complexities and potential complications associated with shunt placement, including air embolism, arterial dissection, and thromboembolism are possible.

Although reduced anastomosis times can be achieved with eversion CE, it is has not been definitively established that neurological outcomes are better. Some studies however raise this possibility. Shah and colleagues ${ }^{75}$ found that eversion CE was an independent predictor of better outcomes, and reported a $1.7 \%$ incidence of perioperative neurological events in eversion CE compared to a $5.5 \%$ incidence with conventional CE. ${ }^{48}$ The authors of other studies have reported improved neurological outcomes with eversion $\mathrm{CE}$, but these findings were not statistically significant. ${ }^{17,24,59,68,75}$ Shorter clamp times can also be useful for anesthesia, because it gives greater predictability in the length of the procedure, and a reduced likelihood of protracted ischemia. This makes the local anesthesia option more attractive, but does not completely eliminate the need for a shunt.

\section{Advantages and Limitations of CE}

Eversion CE is also helpful when significant carotid redundancy is encountered. ${ }^{22}$ This can be treated by either extending the proximal heel of the transected ICA or by resecting an arterial segment. In these circumstances, great attention must be made to the direction and angle of transection so as not to place the ICA in forced rotation. A garret line or pen marking may help in planning these maneuvers.

A number of concerns have been expressed regarding the eversion $\mathrm{CE}$ technique. The most serious two are that management of the distal end point is limited, and that the technique prevents or at least greatly complicates the ability to use an intraoperative shunt.

Access and visibility of the plaque end point is obviously critical. If poorly visualized, it is possible to leave residual plaque, which may act as a flap, intraluminal thrombus, or carotid occlusion, all of which may lead to stroke. Provided that the basic surgical principles are strictly followed, including an understanding of the level of the bifurcation and extent of the disease and making sure that the exposure is adequate, there is no reason why excellent end point visibility should not be obtained. Another factor important in realizing this goal is the presence of an experienced assistant. Because the plaque is removed through a tractioneversion method, it is difficult to achieve this and to maintain complete eversion for end point inspection when operating solo. The tapered shape of the delivered plaque in addition to the intimal lining both provide evidence of complete plaque removal. Accessibility of the end point may be challenging if the Etheredge ${ }^{35}$ technique is used with transection of the distal CCA, and requires simultaneous eversion of the ICA and ECA (Fig. 7).

Shunt placement is designed to maintain sufficient ipsilateral perfusion to prevent ischemia. There are many different types and techniques, but the usual method involves cannulating the ICA and the CCA and performing the operation around the device. A longitudinal arteriotomy lends itself to this maneuver as the vessel is still in continuity and essentially fixed. With a mobile ICA, however, shunt placement can be awkward and problematic, although not all eversion CE advocates agree with this. ${ }^{22,59}$ To get around this, a surgeon can perform the distal endarterectomy first and then place the shunt, or one can proceed quickly without a shunt, utilizing hypertensive treatment to maximize collateral perfuson. ${ }^{35}$

It has also been claimed that cranial nerve injury may be more prevalent with eversion CE. This however has not been substantiated in the largest trials comparing eversion and conventional CE. ${ }^{17,75}$ Although the extent of dissection of the ICA back wall is greater in eversion CE, the visibility is also greater because the final dissection is performed with a truncated and mobile ICA.

\section{Conclusions}

Open surgery for CA stenosis remains a highly effective treatment, with benchmark results provided by the conventional approach. Excellent medium-term results have also been achieved with the eversion technique, which is particularly efficient in avoiding iatrogenic stenosis and in deal- 
ing with redundancy of the carotid, although routine use of a shunt may be more difficult. Based on the current data, eversion $\mathrm{CE}$ appears to have a definite future in the surgical management of carotid stenosis.

\section{References}

1. AbuRahma AF, Jennings TG, Wulu JT, Tarakji L, Robinson PA: Redo carotid endarterectomy versus primary carotid endarterectomy. Stroke 32:2787-2792, 2001

2. Ackerstaff RGA: The significance of microemboli detection by means of transcranial Doppler ultrasonography monitoring in carotid endarterectomy. J Vasc Surg 21:963-969, 1995

3. Archie JP: Carotid patching: what is the optimum patch material? Perspect Vasc Surg Endovasc Ther 10:111-118, 1999

4. Bailes JE: Carotid endarterectomy. Neurosurgery 50:1290-1295, 2002

5. Ballotta E, DaGiau G, Saladini M, Abbruzzese E, Renon L, Toniato A: Carotid endarterectomy with patch closure versus carotid eversion endarterectomy and reimplantation: a prospective randomized study. Surgery 125:271-279, 1999

6. Ballotta E, Renon L, Da Giau G, Toniato A, Baracchini C, Abbruzzese $\mathrm{E}$, et al: A prospective randomized study on bilateral carotid endarterectomy: patching versus eversion. Ann Surg 232: 119-125, 2000

7. Balzer K: Eversion versus conventional carotid endarterectomy, in Horsch S, Ktenidis K (eds): Perioperative Monitoring in Carotid Surgery: Methods, Limits, and Results; Long-Term Results in Carotid Surgery. Heidelberg: Springer, 1998, pp $159-165$

8. Bann J, Thompson JM, Reul GJ, Cooley DA, Brand R, Henderson MC, et al: Vessel wall and flow characteristics after carotid endarterectomy: eversion endarterectomy compared with Dacron patch plasty. Eur J Vasc Endovasc Surg 13:583591, 1997

9. Baracchini D, Toniatio A, Ballotta E: Regarding: "Initial experience with eversion carotid endarterectomy: absence of a learning curve for the first 100 patients." J Vasc Surg 43:1078-1079, 2006

10. Biller J, Feinberg WM, Castaldo JE, Whittemore AD, Harbaugh RE, Dempsey RJ, et al: Guidelines for carotid endarterectomy: a statement for healthcare professionals from a Special Writing Group of the Stroke Council, American Heart Association. Circulation 97:501-509, 1998

11. Bladin CF, Chambers BR: Frequency and pathogenesis of hemodynamic stroke. Stroke 25:2179-2182, 1994

12. Bond R, Rerkasem K, Naylor AR, Aburahma AF, Rothwell PM: Systematic review of randomized controlled trials of patch angioplasty versus primary closure and different types of patch materials during carotid endarterectomy. J Vasc Surg 40:1126-1135, 2004

13. Bourke BM, Crimmins DC: Overnight hospital stay for carotid endarterectomy. Med J Aust 168:157-160, 1998

14. Brott TG, Brown RD Jr, Meyer FB, Miller DA, Cloft HJ, Sullivan TM: Carotid revascularization for prevention of stroke: carotid endarterectomy and carotid artery stenting. Mayo Clinic Proc 79: 1197-1208, 2004

15. Brown KR, Kresowik TF, Chin MH, Kresowik RA, Grund SL, Hendel ME: Multistate population-based outcomes of combined carotid endarterectomy and coronary artery bypass. J Vasc Surg 37:32-39, 2003

16. Cao P, Giordano G, De Rango P, Zannetti S, Chiesa R, Coppi G, et al: A randomized study on eversion versus standard carotid endarterectomy: study design and preliminary results: the EVEREST Trial. J Vasc Surg 27:595-605, 1998

17. Cao PG, de Rango P, Zannetti S, Giordano G, Ricci S, Celani MG: Eversion versus conventional carotid endarterectomy for preventing stroke. Cochrane Database Syst Rev 1:CD001921, 2001

18. Carrea R, Molins M, Murphy G: Surgical treatment of spontaneous thrombosis of the internal carotid artery in the neck. Caroticocarotida anastomosis. Report of a case. Acta Neurol La Am 1:71-78, 1955

19. CASANOVA Study Group: Carotid surgery versus medical therapy in asymptomatic carotid stenosis. Stroke 22:1229-1235, 1991

20. Cheng MA, Theard MA, Tempelhoff R: Anesthesia for carotid endarterectomy: a survey. J Neurosurg Anesthesiol 9:211-216, 1997

21. Cho I, Smullens SN, Streletz LJ, Fariello RG: The value of intraoperative EEG monitoring during carotid endarterectomy. Ann Neurol 20:508-512, 1986

22. Connolly JE: The evolution of extracranial carotid artery surgery as seen by one surgeon over the past 40 years. Surgeon 1: 249-258, 2003

23. Coutts SB, Hill MD, Hu WY: Hyperperfusion syndrome: towards a stricter definition. Neurosurgery 53:1053-1060, 2003

24. Darling RC III, Paty PS, Shah DM, Chang BB, Leather RP: Eversion endarterectomy of the internal carotid artery: technique and results in 449 procedures. Surgery 120:635-640, 1996

25. Darling RC III, Paty PSK, Roddy SP, Ozsvath KJ, Mehta M, Kreienberg PB, et al: Eversion endarterectomy in patients requiring coronary artery bypass. Peripheral Vascular Surgical Society Meeting, 2002 (Abstract \#22)

26. Davies MJ, Mooney PH, Scott DA, Silbert BS, Cook RJ: Neurologic changes during carotid endarterectomy under cervical block predict high risk of postoperative stroke. Anesthesiology 78:829-833, 1993

27. DeBakey ME: Carotid endarterectomy revisited. J Endovasc Surg 3:4, 1996

28. DeBakey ME: Successful carotid endarterectomy for cerebrovascular insufficiency. Nineteen-year follow-up. JAMA 233: 1083-1085, 1975

29. DeBakey ME, Crawford ES, Cooley DA, Morris GC Jr: Surgical considerations of occlusive disease of innominate, carotid, subclavian and vertebral arteries. Ann Surg 149: 690-710, 1959

30. Dixon S, Pais SO, Raviola C, Gomes A, Machleder HI, Baker JD, et al: Natural history of nonstenotic, asymptomatic ulcerative lesions of the carotid artery. A further analysis. Arch Surg 117: 1493-1498, 1982

31. Eastcott HH, Pickering GW, Rob CG: Reconstruction of internal carotid artery in a patient with intermittent attacks of hemiplegia. Lancet 267:994-996, 1954

32. Easton D, Sherman DG: Stroke and mortality rate in carotid endarterectomy: 228 consecutive operations. Stroke 8:565-568, 1977

33. Ecker RD, Pichelmann MA, Meissner I, Meyer FB: Durability of carotid endarterectomy. Stroke 34:2941-2944, 2003

34. Entz L, Járányi Z, Nemes A: Comparison of perioperative results obtained with carotid eversion endarterectomy and with conventional patch plasty. Cardiovasc Surg 5:16-20, 1997

35. Etheredge SN: A simple technic for carotid endarterectomy. Am J Surg 120:275-278, 1970

36. European Carotid Surgery Trialists' Collaborative Group: MRC European Carotid Surgery Trial: interim results for symptomatic patients with severe (70-99\%) or with mild (0-29\%) carotid stenosis. Lancet 337:1235-1243, 1991

37. Executive Committee for the Asymptomatic Carotid Atherosclerosis Study: Endarterectomy for asymptomatic carotid artery stenosis. JAMA 273:1421-1428, 1995

38. Fessler RD, Fernando GD: Carotid endarterectomy, in Kaye AH, Black PM (eds): Operative Neurosurgery. London: Harcourt, 2000, Vol 2, pp 1179-1187

39. Fisher M: Occlusion of the internal carotid artery. AMA Arch Neurol Psychiatry 65:346-377, 1951 
40. Friedman JA, Anderson RE, Meyer FB: Techniques of intraoperative cerebral blood flow measurement. Neurosurg Focus 9(5): E4, 2000

41. Friedman SG: Clinical application of eversion carotid endarterectomy. Vasc Endovascular Surg 37:239-244, 2003

42. Gaunt ME, Martin PJ, Smith JL, Rimmer T, Cherryman G, Ratliff DA, et al: Clinical relevance of intraoperative embolization detected by transcranial Doppler ultrasonography during carotid endarterectomy: a prospective study of 100 patients. Br J Surg 81:1435-1439, 1994

43. Grace PA: Fifty years of carotid surgery-hail and farewell? Ir J Med Sci 173:75-77, 2004

44. Halliday A, Mansfield A, Marro J, Peto C, Peto R, Potter J, et al: Prevention of disabling and fatal strokes by successful carotid endarterectomy in patients without recent neurological symptoms: randomised controlled trial. Lancet 363:1491-1502, 2004

45. Katras T, Baltazar U, Rush DS, Sutterfield WC, Harvill LM, Stanton PE Jr: Durability of eversion carotid endarterectomy: comparison of primary closure and carotid patch angioplasty. J Vasc Surg 34:453-458, 2001

46. Kazprzak F, Raithel D: Eversion carotid endarterectomy. Technique and early results. J Cardiovasc Surg 30:495, 1989

47. Kerber CW, Cromwell LD, Loehden OL: Catheter dilatation of proximal carotid stenosis during distal bifurcation endarterectomy. AJNR Am J Neuroradiol 1:348-349, 1980

48. Kieny R, Seiller C, Petit H: Evolution of carotid restenosis after endarterectomy. Cardiovasc Surg 2:555-560, 1994

49. Koskas F, Kieffer E: Carotid eversion endarterectomy: should we abandon the standard technique? Perspect Vasc Surg 13: 115-126, 2000

50. Koskas F, Kieffer E, Bahnini A, Ruotolo C, Rancurel G: Carotid eversion endarterectomy: short- and long-term results. Ann Vasc Surg 9:9-15, 1995

51. Lam AM, Manninen PH, Ferguson GG, Nantau W: Monitoring electrophysiologic function during carotid endarterectomy: a comparison of somatosensory evoked potentials and conventional electroencephalogram. Anesthesiology 75:15-21, 1991

52. Levi CR, O’Malley HM, Fell G, Roberts AK, Hoare MC, Royle JP, et al: Transcranial Doppler detected cerebral microembolism following carotid endarterectomy. High microembolic signal loads predict postoperative cerebral ischaemia. Brain 120:621629, 1997

53. Littooy FN, Gagovic V, Sandu C, Mansour A, Kang S, Greisler HP: Comparison of standard carotid endarterectomy with Dacron patch angioplasty versus eversion carotid endarterectomy during a 4-year period. Am Surg 70:181-185, 2004

54. LoGerfo FW: Carotid stents: unleashed, unproven. Circulation 116:1596-1601, 2007

55. Lord RS: Short-stay carotid endarterectomy. Med J Aust 168: 149-150, 1998

56. Maharaj D, Ramdass MJ, Naraynsingh V: Carotid endarterectomy using the eversion method: technique and advantages. Internet $\mathbf{J}$ Surg 2:2, 2001

57. Manninen PH, Tan TK, Sarjeant RM: Somatosensory evoked potential monitoring during carotid endarterectomy in patients with a stroke. Anesth Analg 93:39-44, 2001

58. Mas JL, Chatellier G, Beyssen B, Branchereau A, Moulin T, Becquemin JP, et al: Endarterectomy versus stenting in patients with symptomatic severe carotid stenosis. N Engl J Med 355: 1660-1671, 2006

59. Mehta M, Roddy SP, Darling RC III, Paty PS, Kreienberg PB, Ozsvath KJ, et al: Safety and efficacy of eversion carotid endarterectomy for the treatment of recurrent stenosis: 20-year experience. Ann Vasc Surg 19:492-498, 2005

60. Meyer FB: Atlas of Neurosurgery: Basic Approaches to Cranial and Vascular Procedures. Philadelphia: Churchill Livingstone, 1999, pp 307-323

61. Mocco J, Wilson DA, Komotar RJ, Zurica J, Mack WJ, Halazun
HJ, et al: Predictors of neurocognitive decline after carotid endarterectomy. Neurosurgery 58:844-850, 2006

62. Moore WS, Boren C, Malone JM, Roon AJ, Eisenberg R, Goldstone J, et al: Natural history of nonstenotic, asymptomatic, ulcerative lesions of carotid artery. Arch Surg 113:1352-1359, 1978

63. Munro FJ, Makin AP, Reid J: Airway problems after carotid endarterectomy. Br J Anaesth 76:156-159, 1996

64. North American Symptomatic Carotid Endarterectomy Trial Collaborators: Beneficial effect of carotid endarterectomy in symptomatic patients with high-grade carotid stenosis. N Engl J Med 325:445-453, 1991

65. O'Hara PJ, Hertzer NR, Krajewski LP, Beven EG: Saphenous vein patch rupture after carotid endarterectomy. J Vasc Surg 15:504-509, 1992

66. Osborne AG: Diagnostic Cerebral Angiography, ed 2. Philadelphia: Lippincott Williams \& Wilkins, 1999, pp 57-82

67. Ouriel K, Hertzer NR, Beven EG, O'Hara PJ, Krajewski LP, Clair DG, et al: Preprocedural risk stratification identifying an appropriate population for carotid stenting. J Vasc Surg 33:728-732, 2001

68. Radak D, Radevic B, Sternic N, Vucurevic G, Petrovic B, Ilijevski $\mathrm{N}$, et al: Single center experience on eversion versus standard carotid endarterectomy: a prospective non-randomized study. Cardiovasc Surg 8:422-428, 2000

69. Radak DJ, Ilijevski NS, Nenezic D, Popov P, Vucurevic G, Gajin $\mathrm{P}$, et al: Temporal trends in eversion carotid endarterectomy for carotid atherosclerosis: single-center experience with 5,034 patients. Vascular 15:205-210, 2007

70. Rothwell PM, Slattery J, Warlow CP: Clinical and angiographic predictors of stroke and death from carotid endarterectomy: systematic review. BMJ 315:1571-1577, 1997

71. Salvian AJ, Taylor DC, Hsiang YN, Hildebrand HD, Litherland HK, Humer MF, et al: Selective shunting with EEG monitoring is safer than routine shunting for carotid endarterectomy. Cardiovasc Surg 5:481-485, 1997

72. Schanzer A, Hoel A, Owens CD, Wake N, Nguyen LL, Conte M, et al: Restenosis after carotid endarterectomy performed with routine intraoperative duplex ultrasonography and arterial patch closure: a contemporary series. Vasc Endovascular Surg 41: 200-205, 2007

73. Schirmer CM, Malek AM: Wall shear stress gradient analysis within an idealized stenosis using non-Newtonian flow. Neurosurgery 61:853-864, 2007

74. Senkowsky J, Bell WH III, Kerstein MD: Normal angiograms and carotid pathology. Am Surg 56:726-729, 1990

75. Shah DM, Darling RC III, Chang BB, Paty PSK, Kreienberg PB, Lloyd WE, et al: Carotid endarterectomy by eversion technique: its safety and durability. Ann Surg 228:471-478, 1998

76. Solomon RA, Loftus C, Quest DO, Correll JW: Incidence and etiology of intracerebral hemorrhage following carotid endarterectomy. J Neurosurg 64:29-34, 1986

77. SPACE Collaborative Group, Ringleb PA, Allenberg J, Brückmann $\mathrm{H}$, Eckstein $\mathrm{HH}$, Fraedrich G, et al: 30 day results from the SPACE trial of stent-protected angioplasty versus carotid endarterectomy in symptomatic patients: a randomised non-inferiority trial. Lancet 368:1239-1247, 2006

78. Spencer MP: Transcranial Doppler monitoring and causes of stroke from carotid endarterectomy. Stroke 28:685-691, 1997

79. Stoneham MD, Knighton JD: Regional anaesthesia for carotid endarterectomy. Br J Anaesth 82:910-919, 1999

80. Sundt TM, Sandok BA, Whisnant JP: Carotid endarterectomy. Complications and preoperative assessment of risk. Mayo Clin Proc 50:301-306, 1975

81. Szabo A, Brazda E, Dosa E, Apor A, Szabolcs Z, Entz L: Long term restenosis rate of eversion endarterectomy on the internal carotid artery. Eur J Vasc Endovasc Surg 27:537-539, 2004

82. Taylor S, Alcocer F, Jordan WD Jr: Controversies in carotid stenting. Vasc Endovascular Surg 37:79-87, 2003

83. Van der Scaff IC, Horn J, Moll FL, Ackerstaff RG, Antonius Car- 


\section{J. A. Curtis and K. Johansen}

otid Endarterectomy Angioplasty and Stenting Study Group: Transcranial Doppler monitoring after carotid endarterectomy. Ann Vasc Surg 19:19-24, 2005

84. Vanmaele RG, Van Schil PE, DeMaeseneer MG, Meese G, Lehert P, Van Look RF: Division-endarterectomy-anastomosis of the internal carotid artery: a prospective randomized comparative study. Cardiovasc Surg 2:573-581, 1994

85. Wellman BJ, Loftus CM, Kresowik TF, Todd M, Granner MA: The differences in electroencephalographic changes in patients undergoing carotid endarterectomies while under local versus general anesthesia. Neurosurgery 43:769-775, 1998

86. Whitney EG, Brophy CM, Kahn EM, Whitney DG: Inadequate cerebral perfusion is an unlikely cause of perioperative stroke. Ann Vasc Surg 11:109-114, 1997

87. Yadav JS, Wholey MH, Kuntz RE, Fayad P, Katzen BT, Mishkel GJ, et al: Protected carotid-artery stenting versus endarterectomy in high-risk patients. $\mathbf{N}$ Engl J Med 351: 1493-1501, 2004

Manuscript submitted November 15, 2007.

Accepted December 18, 2007

Address correspondence to: Jonathan Andrew Curtis, F.R.A.C.S., 11 Bell Avenue, Lindfield, 2070, New South Wales, Australia. email: curtis_ja@yahoo.com.au. 